\title{
Poesía Peruana 1960 (Antología)
}

\author{
Por Estuardo NúÑ̃z
}

\section{PRESENTACION}

El Depariamento de Literatura ha confeccionado esia Antología tomada de los libros peruanos de poesía editados en el transcurso del año de 1960. Señalar un límite temporal -un período anual- no deja de ser una arbitrariedad tratándose de enfocar la obra superior del espíritu como es la producción lírica. Pero no es intención de este trabajo ofrecer un cuadro completo de lo que actualmente se crea en poesía, sino únicamente mostrar la cosecha ds un año de producción bibliográfica poética y resaltar el hecho de que lo producidoeluce alta calidad que el índice estadístico supera en do numórico a los años anteriores.

Se ha procurado una selección de los poemas más representativos a fin de ofrecer un cuadro de conjunto de uno de los años más profícuos de producción poética en los últimos decenios, que alcanza a casi una treintena de volúmenes. No se quiera encontrar en ella a todos los poetas de alguna significación que figuran en la vida intelectual del país; solamente se consignon $\alpha$ los que algo o mucho han publicado en libro durante dicho año.

Debe advertirse que hemos allegado la bibliografía más completa que ha sido posible obtener hasia el momento, aunque no se nos oculta el hecho de que hayan podido editarse algunos libros no consignados en la selección y en la bibliografía adjunta, sobre todo en provincias (Trujillo, Arequipa, Cuzco, principalmente) y que no han llegado lamentablemente a nuestras manos, pese a nuestros esfuerzos. En tal forma, aparentemente la representación de las provincias es insignificante en cantidad. Roramos darnos noticias e información de ella, para completar nuestra bl- 
bliografía y salvar en lo sucesivo estas deficiencias, pues deseamos ofrecer anualmente estas antologías.

La Universidad siente la ineludible obligación de ampliar su acción cultural fuera de las aulas y de vincularse cada vez más estrechamente con todas las expresiones de la cultura nacional actual. La Universidad no es solamente una organización para el estudio del pasado sino un laboratorio para enfocar el presente y planificar el futuro. La actualidad literaria constituye un vasto complejo de fenómenos culturales que deben ser estudiados como realidades vivientes y no sólo como muertas realidades de tiempos pretéritos. La literatura históricamente estudiada ha cedido el paso, en los últimos decenios, al análisis de la obra actual y al estudio de las proyecciones futuras del acontecer literario. Debe insistirse, de acuerdo con estas ideas, en la consideración de que el fenómeno poético del Perú alcanza hoy una inusitada intensidad que merece un estudio comprensivo e inmediato.

Cabe así la observación de que la Universidad juega un papèl importante en el proceso de la producción literaria. Muchos de los poetas recogidos en esta selección se encuentran o estuvieron vinculados a las aulas universitarias como se aprecia por lo menos en un $30 \%$ de los autores de poemas recolectados. Este es un hecho significativo que no debe pasar inadvertido por la crítica.

El conjuntolde la producción acogida en esta antología acusa una alta calidade Esto suporie dos situaciones: la primera, que los poetas con producción anterior a 1960, han editado este año algunos libros que superan a los precedentes, y la segunda, que ha aparecido un número apreciable de nuevos valores poéticos.

De los poetas con libro u obra anterior publicada, han editado obra adicional en 1960: Belli, Bendezú, Carrillo, Florián, Hidalgo, Moreno Jimeno, Romaña, Rose, Salazar B., Samaniego, Scorza, Sologuren Valcárcel y Vega (14).

Los nuevos poetas que se revelan y surgen al conocimiento general son: Cornejo, Chávez de Paz, Espinoza, Gómez, Heraud, Jodorowsky, Ordóñez, Velásquez, Yauri (9).

Han publicado dos libros en 1960; Chávez de Paz, Moreno Jimeno, Salazar B. y Scorza.

Aunque la mayoría de las ediciones se han hecho en Lima, la procedencia de los autores y sus lugares de nacimiento arroja más o menos un $50 \%$ de nacidos en diversos lugares del Perú y otro $50 \%$ de nacidos en Lima. 
Debe añadirse, finalmente, que en el curso de 1960 tuvieron realización 5 concursos poéticos importantes ganados por poetas peruanos: uno continental, dos regionales, el nacional instituído por el Estado (Fomento a la Cultura), y uno institucional convocado por la Federación de Empleados Bancarios del Perú.

El concurso continental fue el titulado "León de Greif", convocado en Caracas, Venezuela, en el que obtuvo el primer puesto Sebastián Salazar Bondy.

En el Concurso "El Poeta joven del Perú", convocado por la revista Cuadernos Trimestrales de Poesía, de Trujillo, obtuvieron el primer puesto los poetas César Calvo, todavía sin libro publicado, con su volumen Poemas bajo tierra, aún inédito, y Javier Heraud, con El Viaje, libro también inédito hasta el momento. El segundo lugar lo consiguió Mario Razetto.

En el Concurso convocado por el Centro Cultural Guadalupe, de Ica, obtuvo el primer premio Juan Gonzalo Rose con su "Canto a Ica".

El premio nacional "José Santos Chocano" en el Concurso de Fomento a la Sultura correspondiente a 1960 no se ha otorgado todavía; en cambio, en ese año se concedió el Premio de 1959, obtenido por Eleodoro Vargas Vicuña, con su libro "Zora", todavía inédito.

En el Concurso institucional de la Federación de Empleados Bancarios se otorgó el primeropremio de Poesía a Ernesto Elías Car-

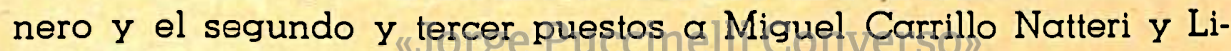
vio Gómez. 
CARLOS GERMAN BELLI (n. 1927)

\section{DENTRO \& FUERA}

Ha llegado el Domingo

y procedo a desollarme como a un oso:

me desenfundo

y exprimo el sucio overol que cubre mi sangre

Caen entonces al fondo de la tina

goterones de sudor frío

pelos erizados

poros entregbiertos por el miedo

$Y$ de inmediato un vererdé césped reemplaza $\mathrm{mi}$ antigua piel

Mi cuerpo extiende su busto durante la noche

$y$ lo hace flotar en posición horizontal hacla el alfétzar de la casa de enfrente

Entonces-veo-músico-escucho-nube$\gamma$-palpo-un-elefante-a-horcajadassobre-uno-de-mis-pelos-erizadosde miedo

Mi cuerpo méase hacia adentro durante la noche e inunda el suelo de sus ptes hasta crecer florecillas como en un invernadero 
FRANCISCO BENDEZU (n. 1927)

\section{ODA A LA TARDE}

Gritas, joh tardel Las muchachas acodadas al balcón, enmudecidas, te perciben, y los autómatas que arden $y$ gimen en azules azoteas anegadas. ¡Cantas solitaria y te desangras!

Yo te he visto clamar sin brazos, $y$ enredarte en los alambres de púas de los desiertos paseos públicos. Yo te he visto forcejear desnuda con un sudor de escarcha en las axilas.

Yo te he visto bailar en los espejos, y correr por plazas de amaranto, $y$ dar una hora sin relojes para las castas parejas que temblaban acosadas por un largo fulgor de telegramas.

Yo te he visto huir $¥$ destrozarte

\section{Biblioteca de Letras}

la trente contra el mármol siniestro de la umbría, y abrazarte, herida, de los postes, y llenar, sentada dulcemente, de hilos y cenizas los estanques.

Yo he rayado tu dramática mejilla con uñas o agujas de diamante, y mordido tus labios purpúreos como espadas; yo he besado tu busto y me he bañado en tu halo de deshechas mariposas.

¿Hacia qué antiguo malecón de cobre conduces, como un aro, la furente y desalada luna del terror? Las mujeres te despiden con los muslos entreabiertos y descalzas, $y$ te escoltan golondrinas y gramótonos. 
¿Qué imposible cintura alucinante persigues en la luz remota y loca? ¿A qué hoguera, ídolo verde, le abalanzas? Cantas y sollozas. IYa no hay nadie! El viento mece columpios oxidados $y$ distantes.

Yo adoré lu trémulo pertil y tus violados ojos de gitana yacente, $y$ el ángel indeleble que salía de lus hombros debajo de los arcos. Yo escupi tu sortija que encandilaba mendigos y mecanógrafas lisiadas con péndulo en la nuca.

Tarde de fotogratías sangrantes y sandalias, |salvel IPalmas a tu paso! |Hosannal |Hosanna! Claveles a tu cuerpo tendido en la literal |Alminares de amor en tu horizonte desollado! IVitor! „Evohé! JEya velar! JAleluya!

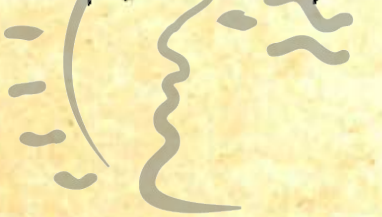

Inédito.

\section{RAUL-ESTUARDO CORNEIO de LetIas}

\section{CARTA PARA IRA AMADA QUE VENDRA}

¡Cuántas veces, a pesar de huírnos, tropezarán nuestros sueños!...

R. E. C.

Amada que vendrás:

No sé aún si el agua de tus ojos inundará estas lineas, pero yo las escribo.

Como una golondrina -viajera de infinitosevoco tu imagen inventada. ¿En qué recodo de distancia te hallarás que no vienes? ¿En qué espejo de misterio te retratará el cielo? ¿En qué pliegues del vestido del sol te retundirán mis sueños de poeta? 
Cuando por fortuna mis ojos adormidos tropiezan con la noche ahí yo te recuerdo.

No sé como serás: śi clara o rubia, ?

pero cuando me arrullan aleteos de rosas gemebundas ahí yo te recuerdo.

Aún sin conocernos, ya nos queremos mucho.

Aún sin que pueda decir:

"La boca ésta que beso es tuya" ya nos queremos mucho.

Aún -sin que podamos balbucir:

"Al fin nos encontramos para siempro ya nos queremos mucho.

Adonde tú estuvieres retén mi voz de arpa. Adonde tú enfilares besa siempre mi frente, Adonde tú arribares acaricia mis sueños.

Para nosotios liaunque se opongalel tiemposiempre habrá una hora rosada.

Para nosotros - aunque : guerree el mundosiempre habrá un trozo de paz.

Para nosotros - aunque el lecho no lleguesiempre habrá un pedazo de sueño.

Cuando menos lo pienses, un día casi gualda habremos de encontrarnos. Yo recordaré tu voz porque sé exactamente cómo parla la rosa. Y tú la mía porque no olvidarás los-plañidos del viento. ¿Entiendes? ¡Me reconocerás!

Aún sin conocernos.

Entonces nos iremos dulcemente perdidos por cualquier triste calle del silencio, indagando tu nombre entre las ramas del alba o de la noche; 
y cuando lo sepa jescucha!. Cuando lo sepa coronaré tu trente con luceros que revelen tu nombre.

Amada que vendrás, tal vez, y que viniste:

si algún día nos vimos

y ya nos conocemos como el viento y la rosa perdóname el olvido.

Mi alma ha surcado tantos ríos de amor que de todo se olvida.

Si algún día, a pesar de huírnos, mis sueños tropezaron con los tuyos, mi boca con tu boca, mi pecho con tu pecho, mis ansias con tus ansias, perdóname el olvido.

Pero la más cercana yez en que quieras tenerme para brindar conmigo un vaso de felicidad, para siempre encontrarnos, para encadenar nuestra sangre, para amarnos de veras, para cantar al Perú, para tabricar la dicha, para enterrat eldolor ¡búscame, búscame, amada mía, a través de una nube Converso"

o a través de una carta!...

De La rosa y el viento.

FRANCISCO CARRILLO (n. 1925)

\section{COMPOSICION I}

Llueve

Llueve en Lima con frívola finura.

Las pequeñas gotas se prenden de los sacos de los oficinistas tristes. Debe ser triste vivir pobre bajo esta lluvia tuberculosa y vana. 
Hoy me dan ganas de entrar en una esquina, tomar café y calentarme el alma;

de encontrar algún amigo, sentarnos a fumar y no hablar nada.

Hoy quisiera también enamorar a una empleada humilde.

Sin embargo, a las muchachas hermosas les gusta caminar ba(jo esta lluvia.

(Recuerdo que una vez, en un lugar donde llovía francamente, pequé en mi alcoba

y la lluvia alrededor me sonreía).

Muchos poetas se inspiran en la lluvia y sufren.

Por ejemplo, a Vallejo le oprimía...

y hay un hermoso cuento de la lluvia.

Pero yo -incoloro burgués- vivo en Chosica, tengo automóvil y me alimento bien todos los días. "

Y este hablar de la lluvia que a otros redime en mí sabe a, fantasía, a tristeza artificial en la vitrina ca de Letras breve combinación de inapetencias

de mi incierta convicción de poesía.

\section{COMPOSICION II}

He vivido tan poco

que aún no estoy formado:

no soy un hombre cullo que digamos,

mi amor está incompleto

y ya me obligo pensar en la muerte

cada año.

He vivido tan poco

que aún todos los días espero

algún noble ideal que ilumine mi vida;

y cuando escribo mis versos vacíos 
- mis innobles deseos ocultando-

busco un hermoso lugar donde ocultarme.

Mi aror está incompleto, ya lo dije, sin duda es mi angustia incoherente que la quiero expresar sin que me llamen necio.

$Y$ si no fuera por mi mujer, por mi mujer y mis hijos que apenas no permiten attsbar estas angustias -tribulaciones de hombre libre sin destino aparenteya hubiera violentado mi vida, mis moradas, en una bacanal de angustia humana, y tal vez así dejara para siempre comprensión más cabal y melancólica.

\section{- COMPOSICION III}

En el jardín de mi casa hay una bella amapola. Es la primera flor que me despierta.

Se dobla con el viento levementes hasta tocar la hlerba. "Jorge Puccineli Converso"

¿Es así la amapola, la dulzura del campo, la paz de mi jardín en el descanso?

Mis hijos - sus trajinesla cohiben.

Mi esposa la protege junto al árbol; ahora se siente menor tímida...

IQué hermosa la ocasión para mi lírical Para hacerle un madrigal a la amapola, a mi esposa una canclón curándole una herida, a mis hijos que se esconden en todos los rincones de mi vida.

De En busca del tema poético. 
DARIO CHAVEZ DE PAZ (n. 1936)

\section{SL, HERMANO VALLEJO}

\section{I}

Sí, hermano Vallejo, mayor de mis hermanos, déjame que te diga el mensaje de mi alma.

He venido a pedirte a solas y a decirte, idame un poco de tu agua para la tierra, hermanol

Hay un campo sagrado que yo poseo en mi alma, donde rocío el trigo que ha de nacer mañana.

Quiero darle a los hombres que coman, quiero darles, sólo un poco del trigo que haya nacido en mi alma.

He venido a pedirte agua para su riego. imirame que no temo tu profunda miradal

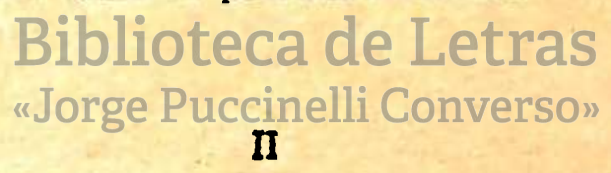

Tu canto no es el canto del cholo de mi tierra, es el canto del hombre del Universo todo.

no hallo en tus palabras peruanos ni españoles, encuentro al *hombre pobre* de este mundo que sangra.

A veces cuando vuelvo mis ojos a la tierra, veo sobre la tierra florecer tus palabras.

$Y$ sus raíces, jcómo se abrazan a los pechos!

y lqué frutos aportan a la causa del hombrel

(el hombre es de la tierra, totalmente terrestre, el hombre no conoce ni hitos ni fronteras). 
III

Veo caer las viejas lágrimas de los hombres, siento ahora su pena que me taladra el alma, son los hombres del mundo que sufren en la hora, del "dame un poco de agua para la sed que ahoga".

Son los hombres del mundo que la miseria acosa, todos los que no saben del pan de cada día, porque hay otros que tienen la tierra que no deben. iHay que luchar hermanos por los hombres del mundol

Hay que luchar es cierto, hay que engrosar las filas, del ejército nuevo del viejo combatiente.

De repente ha venido, no sé desde qué ausencia, una voz que me ha dicho: "Levanta tu materia, sígueme por la ruta del dolor que carcome, vamos por los caminos de espinas y pedradas.

Deja que te conduzca, yo soy la nueva torma, Yo soy el que ha perdidol la soledad de antaño, déjame que te diga de dolor y de pena, déjame que te cuente de amargura y sollozo.

$Y$ pronto hermano mío, estoy en su cruzada, no hay que temer a nadie, es nuestro todo el mundo.

\section{V}

iSilenciol hermano calla, mira que todo calla, un minuto no más por el cholo Vallejo.

I"no sé desde qué ausencia", nos llega su recuerdo, viene como los rayos del sol de madrugada.

cae sobre la tierra más lejana del alma; llena de nuevas voces la ilusión infinita. 
me parece que viene desde la sierra andina, que siendo de Vallejo, es del hombre del mundo;

por eso calla hermano, hombre del mundo todo, "un minuto no más por el cholo Vallejo...")

De Si, hermano Vallejo

\section{ERNESTO ELIAS CARNERO}

\section{Y ES UNA HUELGA GENERAL}

Sobre tus pies, anda, avísale a todos, a todos para que nadie quede en casa, que se salgan, dejando atrás los techos.

Di a los que aguardan, a los que se fueron $y$ están de vacaciones: que el niño deje su seno, la madre el biberón el viejo agote al fin su vida, etras y tú, corre, anda, vuela, dile a todos que ahora sí, que mañana, definitivamente: mañana empieza la huelga, nuestra huelgal

Que se traigan por eso la fiereza, que no dejen la pena en su casa, que se vengan con ella, con todo, con la esperanza en el mástil. con los pañuelos que envolvían la tristeza de sus días domingo; porque mañana, mañana sí, entraremos todos, sin lugar pa:dudas, de ple, en pie, mañana sí entraremos en huelga! 
Y no habrá de ser como las otras penas, esta vez sí nos vestiremos

con el entusiasmo;

una camisa para vencer,

unos zapatos que no tienen hambre

y unas manos para darnos techo.

Porque aun cuando quedemos solos,

con nuestro hambre en medio de la plaza,

esta vez ellos sabrán

que en la sangre tenemos

en ple el último grito,

la última pena que no ha muerto,

porque ya no hay miedo

entra el pueblo.

Porque de tanto dolor que nos dieron

un día sí, otro también,

en pie quedó la revancha

un día sí, otro también.

Diles, diles que les avisen a todos, que si empezamos, de Letras

que si nos toman presos.nverso"

que tiendan el suelo,

que se coman la luz del día,

que todo lo pongan negro.

$Y$ si después, también a ellos

los llevan al paredón.

quedan para eso las mujeres

$Y$. los n!ños

y los ancianos.

$Y$ si a todos los llevan,

y las cárceles se llenan,

que se salgan los muertos

que vacíos queden los cementerios,

porque mañana, sí, mañana

entraremos todos en huelga! 
Y si después de todo

la tierra queda en silencio,

y canta en silencio la victoria,

que las mujeres y los niños,

y los ancianos

$y$ los muertos

pasen primero y coman.

$Y$ cuando todos estén cantando,

triunfantes de mano con la victoria,

que recuerden, que te digan,

que sólo combatiendo

uno se gana el suelo!

$Y$ todo eso es,

como en el empiezo de la vida,

un trozo de universo.

una pausa de cielo

bailando encima del pecho

de tanta gente pobre:

sobre nosotros ballando.

Que digan; diles

que cielo io universa

son las clásicas banderas

que tlotan en el pecho, do los hombres!

Anda, pues,

grítales que se prendan

el entusiasmo,

que hasta la muerte se ponga en armas,

$y$ griten contigo,

$y$ conmigo:

mañana sí, mañana:

entraremos todos en huelgal

Sí, pero tienen que advertir

que esta es una huelga

que no va por salarios:

que va, sí, por tierra,

por la conquista del mundo,

de modo que hasta el silencio 
se quede $\sin$ operar,

sin trabajar en los huecos

de los hombres enterrados.

Será una huelga

que hasta el domingo sobrarál

Corre, hermano, hombre, amigo.

Diles que ninguno quede atrás, $n i_{i}$ se queden sin saberlo.

Que en tus ojos vean,

de antemano

que de tus ojos salió la victoria.

Que te entiendan sin hablarles,

que lo sepan todo;

porque el amor como la huelga,

no necesita de palabras.

Es que ellos aguardaban

que tú se la dijeras:

que al fin

que mañana,

definitivamente,

entraremos en huelgal Letras

Que mañana sí es nuestra huelga.

$Y$ si alguien te dice o pregunta,

proclama que tiene miedo,

dile que te vea los ojos

que descubra en ellos la victoria.

$Y$ grita entonces,

que todos entiendan un solo grito:

pónte vallente la cara,

levanta tu puño,

no des pausa al miedo

levanta todo y levántate.

$Y$ diles que la victoria

na será sólo salario,

sino tu Patrial

La Patria libre al fin,

tan grande que hasta el sol 
le robará sombras!

¡Esa! i Esa es la huelga que empezará mañana!

Es la que esperaban, la que venían guardando cuatro siglos, junto al dolor del campesino, junto a la pluma y la piedra. Y será la última, la que mate al dolor.

Sí, esa será.

Y te ha tocado a $t i$, trabajador bancario, pequeño inmortal que te conoces el camino, que nada temes, que fuiste el primero, que no serás jamás el último.

Anda, informa, hermano.

El pueblo te escogió a ti vocero, corre, ve grita bancario del corazón, federado del alma, Ca de Letras que ahora sí. Puccinelli Converso» que mañana, al fin, empieza la huelga, nuestra grande y definitiva huelga general!

\section{CARLOS ESPINOSA}

\section{POESIAS}

Cuando alguien ríe no sonríe nadie sino mi alma. Cuando alguien llora, nadie deja de llorar, ni siquiera mi alma. Cuando alguien nace, 
flamante a la vida mi alma renace.

Cuando alguien muere, nadie

se libra de morir,

ni siquiera mi alma.

¡Oh plegaria, entre las bóvedas profundas, como duelo musgoso o la rendida estación del firme amante; eres alma cernida sobre los santos frutos de la noche, eso tan espléndido tuyo y tan sangrante;

asumes en la hora postrada que perdura como un bosque, oh plegaria, del corazón el furtivo cuidado, la dicha errante igual a resplandores por el rosiro sudoroso que vigila, cuyo juicio más callado estremece tu ruego, como un pánico de hojas, oh plegaria, todo cielo no turbado!

De Poesias.

\section{Biblioteca de Letras MARIO FLORIANE(n. ugi7) elli Converso»}

\section{¿DONDE PODRE DORMIR BAJO TUS OJOS?}

¿Dónde podré dormir bajo tus ojos?

¿En qué pureza de vida?

(En la tierra, no)... jJunto al murmurio

de tu belleza antigual...

De tu belleza antigua que recuerdo cantando como un gozo en una adelfa niña.

Allí, detrás del tiempo, he de pulir el sueño que era, amiga, como tela de araña donde la noche dejó un temblor de dichal... 


\section{CONDOR, DEIDAD DEL SUR}

Peruano,

americano del Sur:

llámale dios, venera al cóndor.

Has sido de él, derivas de él:

tus brazos pueden convertirse en alas;

del fondo de tu dolor nacerá el vuelo.

Te vió en papel agrario.

Te vió en papel de América...

Te vió, más tarde, esclavo.

Te vió sin las cadenas.

¿Te vió sin las cadenas?

¡Te mira siempre esclavol

¡El cóndor, al mirarte,

te trasmite su empuje libertariol...

iEs por amorl

iDebes amarlol...

- Llámale dios, venera ap cóndor,

hombre de tierra del Sur,

polluelo de cóndor tierra.

¡Al águila, nol

¡No ames jamás al águila!

${ }_{i} E l$ áquila no es tuyal ( ${ }_{i}$ Es extranjeral).

De Escritura para ausentes.

\section{LIVIO GOMEZ}

\section{SOMBRA DE REYES MAGOS}

\section{A Luis Jaime Cisneros}

Regreso, juntando huellas temblorosas, al desván de mis cuadernos aprendices. 
Lueven días desterrados sobre calendarios vacíos, y una polvareda de pascuas se levanta para nublarme el corazón.

Recojo, como mendigo sin limosna, un recuerdo imperturbable, un recuerdo sudando lágrimas, un recuerdo pegado a las vidrieras.

Estiro... y siento cómo unos juguetes recorren sueños abandonados; cómo una escopeta dispara risas; cómo solloza la alegría, redondamente azul, cautiva entre números prohibidos.

Batallones de plomo toman por asalto a la tristeza en sueños que no son míos; mientras mis manos, en la noche descalza, aprietan su caballo de escoba; y mis zapatos, llorando envejecidas distancias, caminan de la mano con su pelota de trapo.

\section{"Jorge Puccinelli Converso"}

$Y$ de pronto, cuando reza el silencio, un tierno pesebre de pétalos se refugia en la nieve tibia, en mi pena; nace una ronda de campanas $y$ crece el amor, inacabable, en la orfandad del tiempo.

\section{PARA UN MUERTO DESCONOCIDO}

Aquí, donde todo afán yace de bruces en la nada; aquí, ya no puede ser más tuya la tierra, el silencio más tuyo, 
nl más de tu memoria

la numerosa paz del olvido.

Ayer no más,

atolondrándose on tus ojos,

en tu sangre,

el sol se precipitaba en tus adentros

tropezando con tu alma,

con los sueños de tus sueños tropezando.

Ayer no más

-en ese ayer que se arruga detrás de los ayeres-.

de tus manos, de tus ansias

se desbordaban los afanes.

Tus afanes de largos sueños largos... largos.

Tus afanes que tal vez fueron

una desvalida esperanza

ya sin esperanzas que ponerse,

$y a \sin$ manos

con que saquearle claridades a la dicha.

Tal vez, en vano, en vano, en vano

quisiste sentir Biblioteca de Letras

cómo ríe una sonrisa

agachándose hasta el alma,

cómo ríe crecida hasta el sollozo,

cómo parpadea

cómo revolotea

Allá,

en lo más cálido del silencio;

allá,

en lo más solo;

allá,

en la más oscura perfecclón del olvido,

jcómo se desmorona tu recuerdol

desde el fondo fugaz de la alegría.

Nublándose tu nombre en los correos, $y$ en las conversaciones 
$y$ en las conversactones, nublándose, nublándose, ya eres algo que arrastran las ausenclas.

De Infancia del olvido.

\section{JAVIER HERAUD}

\section{EL RIO}

la vida baja como un ancho río ANTONIO MACHADO

1

Yo soy un río voy bajando por las pledras anchas, voy bajando por las rocas duras, por el sendero dibujado por el viento.

\section{Biblioteca de Letras}

Hoy árboles or mi

alrededor sombreados

por la lluvira.

Yo soy un río,

bajo cada vez más

furlosamente,

más violentamente

bajo

cada vez que un

puente me refleja

en sus arcos.

Yo soy un río

un rio

un río 
cristalino en la

mañana.

$A$ veces soy

tierno $y$

bondadoso. $\mathrm{Me}$

deslizo suavemente

por los valles fértiles,

doy de beber miles de veces

al ganado, a la gente dócil.

Los niños se me acercan de

día,

$y$

de noche trémulos amantes

apoyan sus ojos en los míos,

y hunden sus brazos

en la oscura claridad

de mis aguas fantasmales.

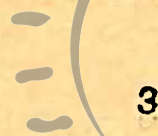

Yo soy el río.

Pero a veces soy

bravo

$y$

fuerte,

pero a veces

no respeto ni a

la vida ni a la

muerte.

Bajo por las

atropelladas cascadas,

bajo con furia $y$ con

rencor,

golpeo contra las

pledras más y más,

las hago una

a una pedazos

interminables.

Los animales

huyen, 


\section{huyen huyendo}

cuando me desbordo

por los campos,

cuando siembro de

pledras pequeñas las

laderas,

cuando

inundo

las casas y los pastos,

cuando

Inundo

las puertas y sus

corazones,

los cuerpos y

sus

corazones.

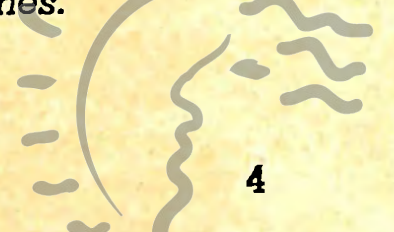

$Y$ es aquí cuando

más me precipito.

Cuando puedo llegar

a los corazones,

cuando puedo

cogerlos por la

sangre,

cuando puedo

mirarlos desde

adentro.

Y $\mathrm{ml}$ furia se

torna apacible,

$y$ me vuelvo

árbol,

y me estanco

como un árbol,

y me silencio

como una piedra,

y callo como una

rosa sin espinas. 
Yo soy un río.

Yo soy el río

eterno de la

dicha. Ya siento

las brisas cercanas,

yo siento el viento

en mis mejillas,

y mi viaje a través

de montes, ríos,

lagos y praderas

se torna inacabable.

Yo soy el río que viaja en las riberas,

árbol o piedra seca

yo soy el río que viaja en las orillas,

puerta o corazón abierto

Yo soy el río que viaja por los pastos,

floro rosa cortada

yo soy el río que viaja por las calles, tierra bcielo mojado Converso"

yo soy el río que viaja por los montes, roca o sal quemada

yo soy el río que viaja por las casas, mesa o silla colgada

yo soy el río que viaja dentro de los hombres,

árbol truta

mesa piedra

mesa corazón

corazón y puerta

retornados.

7

Yo soy el río que canta

al mediodía y a los 
hombres,

que canta ante sus

tumbas,

el que vuelve su rostro

ante los cauces sagrados.

Yo soy el río anochecido.

Ya bajo por las hondas quebradas, por los ignotos pueblos olvidados, por las ciudades atestadas de público en las vitrinas.

Yo soy el río,

ya voy por las praderas, hay árboles a mi alrededor cubiertos de palomas, los árboles cantan con el río, los árboles cantande Letras coñ mi corazón do pájaroverso" los ríos cantan con $\mathrm{mls}$ brazos.

Llegará la hora en que tendré que desembocar en los océanos, que mezclar mis aguas limpias con sus aguas turbias, que tendré que silenclar mi canto luminoso, que tendré que acallar 
mis gritos turiosos al alba de todos los días, que clarear mis ojos con el mar.

El día llegará, $y$ en los mares inmensos no veré más mis campos fértiles, no veré mis árboles verdes, mi viento cercano, mi cielo claro, mi lago oscuro, $\mathrm{ml}$ sol, mis nubes, ni veré nada, nada, únicamente el cielo azul, inmenso,

$y$ todo se disolverá en una llanura dè agua, en donde un canto o un poema más sólo serán tíos pequeños que bajan, ríos caudalosos que bajan a juntarse en mis nuevas aguas luminosas, en mis nuevas aguas apagadas:

De El ría.

ALBERTO HIDALGO (n. 1893)

CANTO A MACHU PICCHU

II

¿Quiénes

qué otros gigantes

sino los que estuvieron en la inauguración de mi atavismo 
trajeron estas cimas

y las dejaron suspendidas en su propio suceso

clavadas

remachadas en el tiempo

soldadas al vacío

cohesionadas con su mismidad?

\author{
¿Quiénes \\ sino los forjadores de mi casta \\ pusieron estos ríos allá abajo \\ estas alturas acá arriba \\ y fabricaron esos campos \\ e hicieron funcionar a estas vicuñas \\ $y$ edificaron estas flores \\ $y$ dieron cuerda a estos caminos \\ que sin error siquiera de un millímetro \\ conducen siempre al corazón del pueblo? \\ ¿Quiénes \\ sino mis prehistóricos \\ mis madrugantes de milenios \\ los anticipadores de mi trente \\ amontonaron tanta claridad \\ redujeron a escombros tanto fímiteonverso" \\ trasportaron aquí tanta distancia \\ se hicieron ciudadanos de tanta inmensidad \\ almacenaron tantas intemperies \\ distribuyeron tantos climas \\ tanto cielo acercaron a la tierra \\ pusieron en sus hombros tanta atmósfera \\ y tanta paz en tanta tempestad? \\ ¿Quiénes \\ sino ellos \\ se ponían duelos \\ cuando alcanzaban una meta \\ porque ya nada había por vencer? \\ ¿Quiénes \\ sino ellos
}


dictaron normas a los elementos para que entendieran con los seres como viejos amigos?

¿Quiénes los devolvieron a la escuela a los ríos para que reaprendiesen su alfabeto de andar por entre el agua?

¿Quiénes lograron que los terremotos tuviesen siempre en cuenta los intereses de su arquitectura acomodando a éstos las expansiones de sus movimientos?

¿Qulénes modificaron las sustancias y dieron a las cosas una estructura física distinta?

A nuestro planeta ¿quiénes lo hicieron a su semejanza?

¿Quiénes crearon otra vez la tierra?

Fueron los míos.

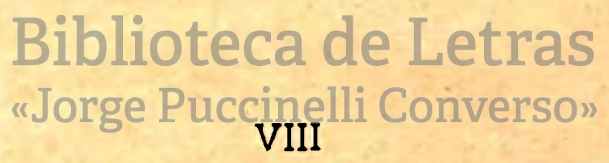

El objeto de Machu Picchu fue el de independizarse de la tierra y no tampoco depender del cielo

Sin sospecharlo hicieron un satélite pero asido tijado a su planeta

Se adelantaron un billón de fechas a los científicos de ahora sólo que colocándolo en una órbita estática inmutable

Por eso Machu Picchu no es de nuestro dominio es un cuerpo astronáutico pegado a nuestra esfera con un cemento como de raíces es sin embargo un principal del que ella es suplemento 
El globo entero está a sus pies rindiéndole homenaje alzando la cabeza para mirarlo como un niño a un grande Machu Picchu está encima con vanidad quizás por la ventaja que le da el ser balcón sobre un buen patio

Una ciudad saqueada por sus descubridores que se quedó reflexionando

Lo tiene todo Arriba

la gloria sorprendida que la inciensa abajo el pueblo que la conmemora Para habitarla se podría enviarle sólo a los pobres que se mueren pues exclusivamente son espíritus prohibir bajo pena de suicidio la entrada de los ricos porque ellos son los únicos que en el caos se viven

Una ciudad sentada en un sillón pero que está conjunta para sus consecuencias hubo saqueo y esto se halla intacto etras hay resultados porque la queremosnverso"

\section{IX}

¿Qué materiales emplearon para alzar estas cúspides estas tapias sonámbulas que van por las cornisas sin caerse?

Antes que nada la energía

de la que grandes almacenamientos tenían en el pecho La necesidad

es decir

el estado sutil de toda obra

la larva de que vuela el edificio

$y$ sin la cual se descimienta

- más aún se innecesaria y cae

La facultad de concederle su condecoración a la altitud 
El deseo diabólico de bajarle la guardia a lo imposible La autoridad suprema que ejercían sobre todas las cosas de modo que éstas al tomar mandatos

los cumplían sin pausas como si fueran empleadas suyas

El afán de erigir un descansero para interplanetarios los temas siderales que bajaban a mostrar su universo y las meditaciones animales que subian a contrastar su tierra

¿Que ignoraron el hierro? Teniéndolo en la sangre diluído lo incorporaron a las piedras en el sudor con el que las tallaban

Que el vidrio no lo conocieron ¿Lo que se respiraba no tenía la trasparencia que permite ver a través de su cristal auténtico almas objetos y hasta ausencias?

Flores Biblioteca de Letras pusieron flores bajo "las piedras para hacerlas fuertes para que igual que savia las nutriesen y las piedras crecieron hasta volverse emporios destinados a nidos de titanes a albergar corazones que no cabian en los cuerpos y se salian por las claraboyas a competir sin miedo con la sístole y diástole del ámbito de rostro incalculable

Unieron las enormes coyunturas con cementos etéreos tan adhesivos como un sexo a otro más delgados que el modo de mirar más intangibles que la música 
aún más tenues que la poesía verdaderos empastes matemáticos ajustes más allá de la física Así hoy gozamos sus paredes como conservas en su propio jugo iguales en fígura y contenido sólo así mismas semejantes y tan compactas que una sola pieza no podría quedar tan reuni-

Ellos

que trasportaron agujeros para llenarlos de inmediato con sus inmensas determinaciones trajeron asimismo montes sobre los hombros curvos de centurias para que sirviesen a los vientos de congénitos diques $y$ al suelo americano de arquetipos.

\section{RAQUEL JODOROWSKY}

\section{De Patria completa.}

\section{BI EL PERSONAJE DE DA CAILE}

Como ángeles negros

que la vida no ha tocado

Pasan

caminan por las calles

esos viejos solos

consumidos miserables

que no piden nada

que nunca dicen gracias

esos viejos que van

van porque sí

regalando flores a los desconocidos

arrastrándose en un tiempo de sueño con rostros aplastados por los espejos

Esos viejos con extraños sombreros caídos de una escenografía que ya no se utiliza 


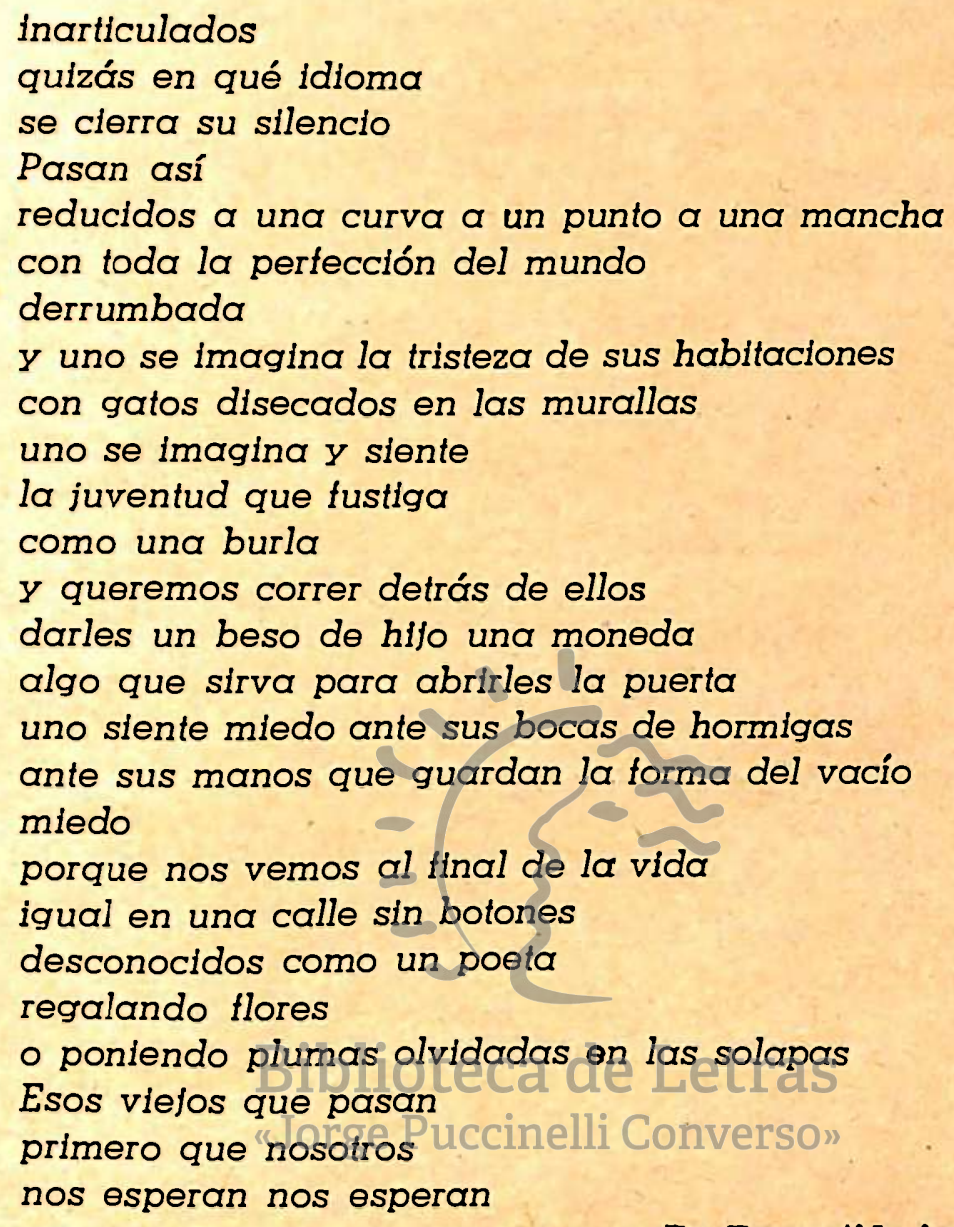

De En sentido inverso

\section{MANUEL MORENO JIMENO (n. 1912)}

\section{ES EL DELIRIO DE LOS DIAS}

\section{I}

Es el delirio de los días cuando de lo creado surge la imagen pavorosa.

No vienen clelos

ni rientes,

vívidas auroras. 
Ahora se agita la voz oscura...

Todo está en llamasl

Funde su metal negro la tormenta.

Las raíces están allí, desnudas.

El ojo ablerto;

la entraña viva.

Es el delirio de los días.

Si la luz cayera... I

Se arremolinan los espacios, las sombras, la lava de la sangre. la carne del dolor.

\section{Biblioteca de Letras}

Nada dettene

la tiniebla lancinante del vencedor.

La estrella: dura

El brazo: alzado.

Están aquí las pisadas del pantano, sus alas tenebrosas.

Ohl Si la luz cayera... I

\section{IV}

Así, callaos!

La límpida hermosura de la tierra resplandece. 
Es el sólo instante en que decae

la gris contienda.

Cuando los sepultos goces

hieren.

De Las citas.

\section{ELVIRA ORDONEZ}

\section{LA PALABRA Y SU FUEGO}

\section{IX}

En este odio estrangulado

ya no hay amor que pueda rescatarnos,

ya no hay sol que disipe nuestras ojeras hondas de rencor.

Hoy que una lava negra modifica la sangre y la consume,

detrás de las ciudades incendiadas

el crimen resplandece como una antorcha inmune

$y$ en los colgantes pies de los ahorcados

balancea el futuro nuestros pasos.

¿En qué infierno mitigar este furor de abismos?

¿Qué ganas de gritar hasta gritar las fístulas del almal

¡Qué ganas de gritar sobre los muertos nuestra elegía sentenciadal

¿Qué ganas de grita

hasta que huya el horrogedespavioridol Converso"

De La palabra y su fuego.

JOSE MARIA DE ROMAÑA

\section{VIANDANTE O CAMINO, NO LO SE}

$A$ veces era yo quien caminaba.

Otras, tal vez, no sé, yo juraría

que era Otro el que andaba y mi vida vivía,

que mi viaje se hacía sin viajero

o el viajero era Otro, en mí, no yo.

¡Por $\mathrm{mi}$ sangre y mis huesosl quiero ser yo,

yo mismo, 
no quiero ser la Mano de Díos para los otros, yo no quiero vivir para otras vidas.

Olvidarme de que existe el dolor $y$ el hombre que lo sufre.

Yo no los engendré.

También yo sufro.

$Y$ no, no puede ser, no puede ser.

Ya mi Dios en la Tierra son ellos.

\section{BARCOS EN FIESTA, ARRIBA, ILUMINADAS}

navegan las estrellas con su música. Yo voy pisando el fondo de la noche, negro racimo unánime, fondo de mar, la arena primitiva, muertos de ojos ablertos, anclas verdes, ciudades de costado, torres trémulas.

Triángulo trintario, aqui está el vértice. Aquí çlerra su beso el universorso" Mis cuatro dedos juntos dan el punto para el compás del círculo infinito.

Aquí está Dios. En torno, la eternidad, el viaje, la violencia, la madre, el sueño, el té con los amigos, el amor y la muerte, las ausenclas, la música, el dolor y los caminos, todos los puertos, todas las palabras, toda la espera, todos los silenctos.

Ya nada importa nada, por Dlos vivol Arrojad al lagar todo mi odio y $\mathrm{mi}$ amor al molino. 
JUAN GONZALO ROSE (n. 1928)

\section{CANTO A ICA}

\section{Estadio Inicial}

$i^{\cdots, \infty}+x^{2}$

Primero tue la mano. La tejedora mano del ofebre moreno que tejía colores

bajo el color del cielo.

La sensitiva mano labradora que conocía todas las caricias del agua, los regios catachismos dinásticos del tuego, y que dejó en la tela, aprisionada, la sencilla epopeya del hombre que una tarde de lentos arcoiris, dibuja sobre un paño la belleza del cielo.

Primero tue la mano. La mano voladora que domeñó la gracia silente de la arcilla y construyó en el vasto sitial de las edacies ' $x$ arquitectura frógil y ritual de sus sueños. Primero tue la mano. Poderosa y pequeña, igual que una semilla.

\section{Eatadio Tenebroso}

Pero la muerte estaba. Como una mosca verde habitaba en el vientre febril de las doncellas. Mordía la dulzura proverbial de los granos.

Pero la muerte estaba en la túnica roja del sacerdote púlido, en la espuma cansada de golpearse los labios. Estaba entre la arena, largamente escondida. 
Pero la muerle estaba, pertinaz, en la mano que tejía la iela y moldeaba la arcilla.

$Y$ hacia la muerte fueron, silenciosas, las manos,

arrastrando con ellas la belleza encendida.

$Y$ comenzó en la noche encantada de América, como un río de luces, el viaje de los fardos.

\section{Estadio del Sol}

No sólo mano y muerte.

No sólo muerte y mano.

Sino que el sol había.

El sol cual un espejo que sólo reflejaba

la luz de los milagros.

En los surcos hervia su perlil de soldado.

En los lemplos, sus igneas colgaduras

el salto de los pumas detuvieron.

El sol. El sol principalmente.

Porque hubo agua de sol en las vasijas.

Porqua hubo miel de sol sobre las redes.

Porque hubo hilos de sol en los telares.

$Y$ hubo tuna de sol para la noche

repetida " Yafugaz do los amanles. "erso"

Y la mano y la muerte conciliaron

bajo el ala del sol sus dos afanes.

\section{Eatadio de la Sangre}

Antes de las espadas,

la muerte era un camino de ciegos caminantes.

Un mapa de fogatas apagadas bajo un cielo de arena.

Apenas si un olvido. El ingreso a la casa de raíces y nidos que habilaban los padres.

Pero advino la espada. Ya la muerte tue sangre.

$Y$ entonces las raíces dieron flores de sangre.

$Y$ entonces de los nidos volaron a los hijos grandes plumas de sangra. 
$Y$ bajo arcos de sangre se marcharon los dioses del reino del silencio el feudo de la sangre.

\section{Estadio de los Navegantes}

Desde la pampa -único lugar de la tierra donde Dios puede andar con los brazos abiertosllegaron una tarde de luz los navegantes.

Un olor a la nieve de embriagadora altura impregnaba sus trajes.

$Y$ llegaron con ellos una copa de vino

$y$ un sonoro contorno de guitarras salvajes.

Y llegaron con ellos libertarios aceros, y el pueblo, como un pueblo,

les brindó sus guerreros.

Recogieron entonces la nítida blancura que preside la arena, recogieron la sangre vertical derramada, y en la orilla nerviosa que apaciguan los mares, bellamente soñaron una nueva bandera.

\section{"Jorge Puccinelli Converso"}

\section{Estadio de las Frutas}

Si el sueño fue bandera, la semilla fue fruto. Con un largo discurso de campanas y aromas la vid sombreó la arena.

El filtro de los llantos redondeó las lagunas, hasta cuyos espejos, del fondo del desierto, llegar suelen las noches a mojarse las penas. Toda antigua dulzura se hizo forma en las frutas. Toda nueva dulzura santigüó las arenas. $Y$ el algodón, de pronto, extendió sobre el suelo su callada costumbre de ser blanco y ser bueno.

- Pero la mano humana -sabia mano del pueblola mano tejedora, la mano labrantía, la mano voladora, 
la mano que enterraba entre incendios los muertos, la mano que la sangre hirió con sus espadas, la mano campesina que fue de mano en mano repartiendo la gracia, vio una noche vacia de sus frutos la mano. Ved el huerlo florido. Ved la mano vacía. Mirad sobre los campos el sol de los negados. Mirad sobre los rios la sed de las floridas cantidades.

Primero tue la mano. Mañana serán manos por las manos unidas. $Y$ el viento de los libres ha de ser como un manto que cubra las ciudades.

Inédito

SEBASTIAN SALAZAR BONDY (n. 1924).

\section{COSTA Y MUJER}

A Irma

Diré que de los mares del Surde Letras salió como un "gnimal allivo Yelestuendesso» esta imperfecta costa, este dios de arenales y piedras, en cuyo seno conozco ahora el amor de una mujer bajo las crepusculares banderas del horizonte oceánico.

Diré también que en esta orilla impasible que el ventarrón solícito viste de tules vertiginosos, de ropas ligeras que ondean en el atardecer, mi mujer y el melancólico paisaje, mi mujer y el sol de oro pulido y terso, mi mujer y el aroma de los peces recién sacados del agua, son un estallido lento de ternura y fiebre que invade cosas, platos, sombras, cada noche.

En la mañana aspiro su cabellera negra, pongo mi boca en su piel bruñida por olas $y$ aires, 
y conquisto el universo de las gaviotas:

pájaros de caricia, aves de amor, volátlles suavidades de sexo $y$

trrumpen en mi cielo y lo embellecen.

(therra

Entonces es como si fuera el fundador de estos parajes

$y$ las llameantes cumbres de los médanos,

cuyos senos, cuyos muslos, cuyo vientre,

pertenecen a la vida como el sueño a la locura.

Creador del litoral soy.

desciendo y toco las playas del Perú,

y toco también la carne de mi mujer

donde se ha encendido el fuego lustral del paraíso.

Costa, mujer, todo es lo mismo en mí.

todo es el sumo hervor de la sustancia humana,

todo es el trémulo trono del deseo

que reina y no se oculta ni cede en su sed de eternidad.

Costa salida de las simas marinas

como un gran animal que despertó al tin de su pereza

y quedóse quieto, a la espera

del amante que tiende su cuerpo en las arenas,

que pisa las rocas conl und amorosa gana de habitarlas,

que rodea a la mujer gon sus brazos, sus piernas sus dulzuras,

bajo las sábanas impecables del verano, socavando a la tierra, a la sangre, al alma,

en un inmenso y poderoso acto de conocimiento y exaltación.

$A h$, costa femenina, mujer terrestre,

amarte ha sido escribir tu nombre en las arcillas de la patria.

De Confidencia en alta vox.

ANTENOR SAMANIEGO (n, 1919)

\section{RUMOR DE LA PALABRA DESGARRADA}

Yo creí ser, hasta hace poco, un hombre distinto de todos.

$Y$ he aquí que donde sufren, sufro; donde rien, río.

Estoy hecho de angustia, de dolor, de hambre, de tristezr... 
No luzco harapos, pero mi te está hecha retazos.

No muestro llagas, pero mi alma está quemada de heridas.

Mis plantas transitan por las calles que otros transitan.

Unas veces me detengo en alguna esquina y miro a todos lados.

Dentro de cada rostro intuyo una penosa resignación.

Todos, como yo, están brutalmente golpeados por la vida.

Me da pena decirlo. Sólo hay un puñado de ricos hombres.

Donde veo un cádillac, pienso: dentro hay un ladrón impune.

Así pienso y desespero. De prisa huyo de la selva humana.

Busca los bordes del mar y lloro y blasfemo y maldigo.

Busco los suaves colores de la tarde y lavo mis sombras.

Creí ser un hombre distinto de todos y soy como ellos,

como los que penan por un pan o por un centavo.

Somos células enfermas de una sociedad miserable.

La sociedad que nos gobierna tiene cabeza de verdugo.

¡Yo os lo digol iCreed en mi palabra llorosa y cálida!

MANUEL SCORZA (n. 1928)

De Rumor de la palabra desgarrada.

\section{Biblerepusculo para âna \\ "Jorge Puccinelli Converșo"}

Sólo para alcanzarte escribí este libro.

Noche a noche,

en la helada madriguera

cavé ml pozo más profundo,

para que surgiera, más alta,

que es mi lamor quien platea por ti el mundo en las mañanas, el agua enamorada de este canto.

Yo sé que un día las gentes querrán saber por qué hay tanto rocío en las praderas, yo sé que un día irán ansiosas a los campos, seguirán los h́llos de los prados, y a través de las florestas llegarán hasta mi pecho, y comprenderán, 
-lo siento, estoy sintiéndolo-

y verás esta hoguera.

Desde ciudades enterradas,

desde salones sumergidas,

desde balcones lejanísimos,

verás este amor,

y escucharás mi voz

ardiendo de hermosura,

y comprenderás que sólo por ti he cantado.

Porque sólo por ti estoy cantando.

iSólo por ti resplandece

¡Sólo para que me veas,

ilumino mi rostro oscurecidol

iSólo para que en algún lugar me mires

enciendo, con mis sueños, esta hogueral

(El Mudo,

El Amargo,

El Que Se Quedaba Silencioso,

te habla ahora a borbotones,

te grita cataratas, inmensidades!ca de Letras

No quiero luz del día, ni diamante encendido, rge Puccinelli Converso"

no quiero no morir:

escucha mi agonía.

Alguna vez amarás,

alguna vez

en las lianas de la ternura enredada

comprenderás que cuando el dolor nos llega,

es imposible hablar;

cuando la vida pesa, las manos pesan:

es imposible escribir.

Mas con los años las escamas se nos caen:

$Y$ un día, al volver el rostro,

vemos a lo lejos,

como remotos barcos encallados, 
cosas que creíamos llevar adentro,

y miramos que son musgo los amores más ardientes.

¡El hombre enceguecido

no escucha las campanas silenciosas de la hierba, hasta que encuentra en los caminos,

como culebra, su antigua piel, y reconoce entre las ruinas su vieja máscara oxidada, $y$ se detiene a recordar lo que amó, $y$ descubre agujeros rotos do eran ojos fulgurantes, porque el tiempo crudelísimo injurió el Rostro Puro, $y$ los años nos pusieron anteojos de melancolía, con los ojos que se mira la ruina, el otoño, la grosura de las mujeres!

1Oh, cruel máscara salobre que aguarda agazapada debajo del rostro del ángel, la tristeza esperando no más, para volcar lás aguas def naufragfol verso"

Surge entonces

el Canto inextinguible, cual surge ahora esta voz que llora por los días hermosos, cuando el agua era azul, y no sabíamos que todo lo nacido morirá.

Todo lo que nace ha de morir. INo digo más porque me entiendesl Tu sabes que sólo quiero que, en algún lugar, leas esta carta, antes que envejezcan los carteros que te buscan a la salida de las iglesias, 
entre las recién casadas,

a la hora del jazmín rendido.

Tuiero que el rayo de mi ternura

traspase con lanza a los que no conozco,

y salte noche hirviendo

a los ojos de los que abran este libro,

$y$ en algún lugar,

un día de este mundo,

me oigas

y te vuelvas,

como quien se vuelve extrañado

al sentir detrós el resplandor de un incendio,

$y$ comprendas que estoy ardiendo por ti, quemándome

sólo para que veas,

desde tan nunca, esta luzl

JAVIER SOLOGUREN (n. 1921)

\section{"Jorge ESTANcIAs Converso" \\ Biblioteca de Letras}

De Los adioses.

IOh Sueño donde las formas pasan como por una avenida

alzada en el crepúsculo, tú me enciendes la sed, los enigmas, los acallados pasos de $\mathrm{mt}$ vidal

\section{6}

Tu ardor, Nieve, en la noche, tu sllencioso ardor.

Hay taniasmas que en "I se echan 
como amantes en la yerba, y no les das allmento que no seo tu silencio: Tu unánime voz secrela.

Cuerpo a cuerpo, Hombre y Mujer, se irán quemando en el fuego blanco del amor.

Mano a mano levantarán el árbol de la vida, y su aire y sus pájaros. Hombre y Mujer, descubriran que el mundo es compañía $y$ un mismo sol calentará sus huesos, $y$ un mismo anhelo los mantendrá despiertos.

\section{Biblioteca de Letras. Es astancias. "Jorge Puccinelli Converso"}

\section{OH, CORAZON}

Oh corazón, røy entre sombras, pastor de signos y de dudas, no se comulga en soledad, tu canto vuelvo por los hombres.

Que en él escuchen el latldo, la brisa de tu sangre.

Oh corazón, oh fuente alada, un alba de vigor y de ternura. desde tu lecho se levante, una aurora teñida con la verdad de tu sangre. 


\title{
PASO LA PRIMAVERA
}

\author{
PASO la primavera, sus prodigios \\ de aladas gemas fuéronse cambiando \\ en pesantez de frutos. El verano \\ hizo valer sus fuegos combativos. \\ Otra estación llegó: Oloño ahora \\ sus sordas humedades va extendiendo, \\ $y$ el árbol es, umbrales del invierno, \\ un grave surtidor de muertas hojas.
}

\section{TE ALISAS, AMOR}

Te alisas, amor, las alas, tus cálidas plumas.

El oro de la tarde está muy quieto; pero la anguslia es mucho cielo. muchas celestes llamas huyendo de tus ojos. Otros países hay de niebla y lejanía, otras comarcas pudriéndose de frutos, otros espacios indecibles, amor: pero Ia angustales mucho rostro, muchos labios diciendo y no diciendo, mucho vuelo amargamente encadenado.

Inéditog

GUSTAVO VALCARCEL (n, 1921)

\section{EL REINO DE LA TIERRA}

A ras de suelo, en el nivel del aire. la luz sea contigo, camarada, minero que alzas tu pedestal de tierra desde el hondón terrible, cuaternario, hasta el altísimo lugar en que se sutre 
de ver al odio, tras grandes martillazos, quebrar al hijo del hombre en pedacitos.

De tanto que tú bajas ya no nos queda altura, minero de la noche, cava el día; de tanto que tú subes vamos perdiendo piso, minero de la aurora, cubre el mundo.

Prometeo de casco invulnerable ponte en guardia, la sed como estandarte; ármate de metal, el hambre al trente; llora con rabia, echando tus penas sobre el hombre; tira la caridad por la bragueta, tocando de paso tu valor; desciende a las entrañas terrenales, sujeto al hilo de tu impalpable llanto: después calienta tu esqueleto al rojo. vivo, afila tu eternidad incontenible, tente en grito, incorpórate, perfílate, dispárate, y ya verás después de todo iqué pasa, camaradal

Obreroscen yunqueideliuturo, verso" minero en fragua de universo, los veo avanzar a golpe rápido, llenos de fuego como el sol.

Hombres de poca te, en verdad os digo: de ellos será el reino de los cielos.

\section{EL REINO DE LOS CIELOS}

Incisivo, voraz, el de los años, antropófago el tiempo, sin fin sus cremalleras, cae agosto blandamente entre cuchillos, luego octubre; de luto riguroso, pasa diclembre y su mirar lejano por fin los doce lobos y de nuevo. 
Muge la vida al son del mataderc se pega el dolor en las pezuñas, sube al tronco, se anida en la cabeza, salta como un tigre por los ojos y allá va... llorando mucho de lo mismo... de ver el dolor en cuatro patas empinarse.

Es la ciudad en que vivimos, el medio de por medio y sus tentáculos, el suburbio de redes tan paupérrimas y la ilusión en mangas de camisa colgada de un alambre en la azotea.

iRelaciones Humanas a estísimas alturas! Masca bruma Pedro,

y Juan de etiqueta masca pedros.

Rumia coca Quispe

y Esparza endomingado rumia quispes.

Bebe llanto Emilio,

y Luis de uniforme bebe emilios.

$Y$ aun si alguien come pan bien escondido, con su pan se lo comen muy tranquilos, $\alpha$ la vista de lodos en cuaresma.

Relaciones Humanas al estísimás alturesto"

El reino de los cielos está aquí y siguen orondos los camellos pasando a carcajadas por el hueco de míseras agujas.

\section{De Sus mejores poemas}

\section{BIELIOGRAFIA}

No se consigna el lugar de publicación si es la ciudad de Limo, ni tampoca el oño, por ser poro todos el de 1960.

BELLI, CARLOS GERMAN.-Dentro \& fuero. Col. Forma y Poesio, 3. Ediciones de lo Escuela de Bellas Artes.

BENDEZU, FRANCISCO. Arte menor. Col, Forma y Poesio. Ediciones de la Escuela de Bellas Artes. 
CARRILLO, FRANCISCO.- En busca del tema poético. Col. Cuadernos del Hontonar, 2. Talleres de Artes Gráficos learo.

CORNEJO, RAUL ESTUARDO.- La rosa y el viento. Poesia. Editorial Son Marcos.

CHAVEZ DE PAZ, DARIO. Tú y yo. Poemas.

Son Marcos.

ESPINOZA, CARLOS. Poesios. Col. Formo y Poesio, 6. Ediciones de la Escuelo de Bellos Artes.

FLORIAN, MARIO. Escritura para ausentes. Compoñio de Impresiones y Publicidad.

GOMEZ, LIVIO.- Infancia del olvido. Col. Cuadernos del Hontonar, 2. Tolleres Icaro.

HERAUD, JAVIER.- El rio. Col. Cuadernos del Hontonar, 1. Talleres Icoro.

HIDAlgo, ALberTo.- Patria completa (Canto a Machu Picchu). Juan Meiio Boco.

JODOROWSKY, RAQUEL.- En sentido inverso. Ediciones EI Oso y la Pajorito.

MORENO JIMENO, MANUEL. - Los citos. Antologios de la Rama Florida, 1. P. L. Villanueva.

Ediciones de la Escuelo de Bellas Artes.

ORDOÑEZ, ELVIRA.- Lo palabra y su fuego. Icaro.

ROMAÑA, JOSE MARIA DE.- En la orilla del tiempo. Ediciones Cruz dol Sur.

ROSE, JUAN GONZALO._- Simple canción. Col. Formo y Poesia, 2. Ediciones de la Escuelo de Bellos Artes.

SALAZAR BONDY, SEBASTIAN.- Confidencio en alta voz. Ediciones Vida y Polobro.

5. Ediciones de lo Escuelo de Bellos Artes.

SAMANIEGO, ANTENOR.- Rumor do la palabra desgarrada. P. L. Villonuevo.

SCORZA, MANUEL. - Los adioses. Col. El Centauro. Festivales del Libro.

Libro.

Las imprecaciones. Col. El Centouro. Festivales del

SOLOGUREN, JAVIER.- Estancias. Col. EI Timonel. Icaro.

VALCARCEL, GUSTAVO.- Sus mejores poemos. Ediciones Perú Nucvo.

VEGA, ALBERTO.- Palabra natal. Arequipo: Ed. Universitorio.

VELAZQUEZ ROJAS, MANUEL.- Lo voz del tiempo. Ediciones Perú Joven.

YAURI MONTERO, MARCOS.-EI mar, la luna y olla. Ediciones Piedro y Nieve. 